\title{
CONNECTING HEARING PARENTS WITH THE DEAF WORLD
}

\author{
Rachel Locker McKee
}

\begin{abstract}
The parental experience of raising a child who is potentially a Deaf community member can be framed in terms of 'migration theory' (Laing, this volume), in contrast to the grief-centred models commonly presented to parents. This migration model is grounded in an understanding that deafness is a culturallinguistic status. Usually responses and advice to parents of Deaf children are framed within a medicalised, deficit paradigm of deafness as an impairment of hearing and speech. This article examines the experiences of parents of Deaf children who are in mainstream schools, investigating the extent to which knowledge about the Deaf community is absent from the images they construct of their Deaf children's identity. I consider whether current opportunities for parents to connect with Deaf world resources afford conditions for a 'migration journey'. The article concludes that mechanisms in the New Zealand education system for connecting hearing parents with the Deaf world need strengthening. In particular, professionals who have Deaf-hearing intercultural skills are crucial in realigning the power imbalance between Deaf and hearing people and shaping positive images and aspirations for Deaf children's futures.
\end{abstract}

'Your Deaf son is your child, but he is of my people.'

\section{INTRODUCTION}

From the standpoint of an anthropologist mother of a Deaf ${ }^{2}$ child, Laing (this volume) proposes that the experience of raising a child who will potentially identify with the Deaf community can be framed in terms of migration theory. This culturally-centred frame is posited as an alternative to the grief-centred models more commonly presented to parents as a way of dealing with their experience. To propose an alternative framework is not to downplay the emo- 
tional trials that parents face in raising a child who is unexpectedly different. As Kyle (1991:17) points out:

$[H]$ earing parents have to cope with loss. At the beginning it is the loss of the hearing child they wanted. Now, it seems, they might even lose the Deaf child they have raised - to the Deaf community, of which the parents have never been a part (...). The problem may be seen as one of a family with a mixed culture, but diagnosing or naming the difficulty does not make it any easier to handle.

Nevertheless Laing posits that undertaking a purposeful journey towards the cultural terrain of the Deaf world supports positive identity and bicultural competence in young Deaf people, and that it also affords a 'frontier' zone for hearing parents who find themselves in a position between cultures. The migration metaphor is grounded in a sociocultural construction of what it means to be Deaf. Relatively few parents, though, are enabled to conceptualise Deaf people - including their child - as participants in a different cultural community. Parents are more likely to try to reconcile their firsthand experience of deafness with the more familiar construct of disability or impairment, and to be guided by cultural imperatives towards 'sameness'.

The value of connecting parents and Deaf children with the cultural knowledge of Deaf role models has long been advocated by Deaf commentators and professionals, and is now supported by educational and sociolinguistic research (Johnson and Erting, 1989, Kuntze, 1998, Mahshie, 1995, Martin and Lytle, 2000, Stewart and Kluwin, 2001, Woodward et al., 1988, Bailes, 1999, Grosjean, 1998, Holcomb, 1997). In the Deaf community, many Deaf children eventually come to discover an easily accessible language of communication (New Zealand Sign Language [NZSL]), a normal sense of identity, and a heritage of collective Deaf ways and knowledge that brings a wider perspective to their personal journey. As commonsense as this connection seems, it is yet a long way from the current reality of most Deaf children and their parents in New Zealand. A Deaf historian, Paddy Ladd (2003: 221), argues that:

Deaf culture [is] completely surrounded and permeated by a majority culture and its materiality, where cultural transmission through ethnicity is problematic and where individual Deaf identity processes are disrupted by a particularly intense form of educational oppression. 
The historical absence of Deaf adults in the Deaf education system, and the domination of oralist pedagogy (an aural-oral approach to communication that eschews signing and a Deaf collective) are prime mechanisms of the oppression to which Ladd refers. The medicalisation of deafness, especially the promotion of cochlear implants as a cure, and the educational push to mainstreaming are also argued to be manifestations of oppression, aiming to assimilate Deaf individuals to hearing norms (e.g., Ladd, 1991, Lane, 1992, Branson and Miller, 1993, Humphries, 1996).

Recognising Deaf adults' capacity to empower Deaf children as learners, particularly by fostering their sign language competence and cultural identity, has followed from recent acknowledgment of a sociocultural paradigm in Deaf education in New Zealand. ${ }^{3}$ Without a tradition of Deaf educators or administrators, however, the structural implications for delivery of bilingualbicultural education and family support are radically challenging. Recent initiatives have included policy consultation with the Deaf community, acceptance of NZSL, the admission of Deaf people to teacher training, and efforts to enable Deaf children and their families to meet Deaf role models. Since few Deaf people are qualified to enter teacher training, Deaf paraprofessionals are employed in innovative roles, such as 'Deaf Mentors'. A national survey of Deaf people in Deaf education in New Zealand (Smith, 2003) reported twelve Deaf qualified teachers $5.5 \%$ of all teaching positions in Deaf education), while Deaf paraprofessionals included eight Language Assistants, eight Teacher Aides, eight Deaf Mentors/Resource persons, and two NZsL tutors. To date, no positions as 'Adviser on Deaf Children', who provide pre-school guidance to families, have been held by culturally Deaf people. Most Deaf staff work in specialist Deaf schools or resource classes, whereas $85 \%$ of Deaf children are enrolled in mainstream classrooms (Stockwell, 2000). Most parents of these children remain unconnected to the Deaf community.

Successful migration requires motivation and opportunities for intercultural interaction. Guidance from bicultural role models, and timely acquisition of cultural knowledge and skills (especially language) are important in making sense of critical encounters. Within available structures of support and advice to parents, motivation and facilitated opportunities for contact with (and insight into) the Deaf world are weak. This situation is neither unique to New Zealand (cf. Beazley and Moore, 1995, Pickersgill, 1997), nor inevitable, as bilingual initiatives overseas have shown (Schleper, 2002, Ahlgren and Hyltenstam, 1994). This article examines parental perceptions of Deaf children's linguistic and social identity which demonstrate a tenuous link to Deaf world perspectives and resources. 
This article draws on data from eight case study interviews and a written survey of 124 parents of Deaf children in mainstream schools, which were collected as part of a larger project that examined access to communication and learning for Deaf children in regular schools. ${ }^{4}$ Taped interviews were transcribed and thematically coded. Survey responses were analysed quantitatively where appropriate and thematically coded in the case of responses to open-ended questions. Comments from eight Deaf Mentors who were interviewed within the larger study are also included (see McKee, 2005).

Analysis of the data considers the extent to which a sociocultural perspective on being Deaf informs parents' images of Deaf children's present and future social experience. It explores whether resources (including information, personal contact, and language skills) currently available to parents of mainstreamed Deaf children afford conditions for a 'migration' to the Deaf world.

I write from the position of a hearing person who works and lives in the Deaf-hearing 'contact zone' - as a professional interpreter, teacher of Deaf and hearing students in Deaf Studies, and wife in a Deaf-hearing marriage. In these roles I have watched and participated in communication between Deaf people and their hearing parents, in various circumstances and stages of the life cycle. I offer here a glimpse into the hearing-Deaf gap in values about cultural identity from an incident in my own family:

My Deaf husband is the son of hearing parents who were exceptionally dedicated and successful in raising him to become an educated professional. Since childhood, he identified strongly as culturally Deaf, which his parents eventually embraced, even forming their own connections with people and causes in the Deaf community. Many years on, when our hearing son (their grandson) was three years old, he began to construct an understanding of the social and linguistic identity of the Deaf and hearing people in our lives. He realised that his Dad and other friends who signed had an extra name - 'Deaf'. Experimenting with his new labelling system, he often described his father as 'my big Deaf friend'. At a family gathering, he proudly announced this. Grandma was not amused, but genuinely upset. She felt that her success in raising her son as a well-integrated member of society was undermined by her grandson overtly identifying his father as Deaf. She insisted that a more healthy description would be 'my father, who happens to be Deaf'. 
Our son, however, had already assimilated his father's attitude that 'Deaf' was a central and positive personal attribute, a way of being and a social category that was identified and discussed in our daily lives. My husband was taken aback by his mother's negative reaction. To him, his son's naïve description was a compliment, and a sign of being a successful Deaf father.

This cross-generational, cross-cultural perception gap is typical within the families of Deaf people. Observing this tension in professional and personal contexts convinces me that introducing hearing parents to the cultural perspective of Deaf people early in their child's life could reduce angst for both generations in the long-run.

This article does not purport to represent the wide spectrum of parents' experiences or possible life paths for Deaf children. Neither does it canvass all of the issues that parents raised in the data set. Attempting to understand participants' constructions of a particular reality and their position within it, this analysis aims to 'provide perspective rather than truth... and context-bound information rather than generalisations' (Patton, 1980:283). I have selected data specifically to focus attention on the interface between parents and Deaf world perspectives, in light of Laing's 'migration' concept. As neither a parent of a Deaf child nor a Deaf person myself, I am acutely aware that dissecting and re-representing Deaf people's and parents' representations of themselves and their children is a delicate task. I offer this analysis with respect for the experiences that they candidly shared with me.

\section{LANGUAGE CHOICES - PATHS TO IDENTITY}

Choice of communication mode is 'the' vexed issue in the interface between parents of Deaf children, professionals, and the Deaf world. Language choices and contingent identity paths for Deaf children are loaded with the beliefs, values and aspirations of those who make the decisions, and those who give advice and provide supporting resources. The decisions of families about communication are vulnerable to potentially disabling or enabling influence from others involved - professionals, family members, or Deaf community members - according to the breadth and depth of information available, and the timing and presentation of it (Beazley and Moore, 1995).

Access to comprehensible language and meaningful interaction is precarious for Deaf children in hearing families and schools, yet is critical in determining educational and social competence. Parents are intuitively aware that the 
language(s) and communities of peers to which Deaf children have exposure will shape their self-concept and identity. The bilingual reality of many successful Deaf adults' lives provides evidence that Deaf children's development is advanced by early use of a visual language (Chamberlain et al., 2000, GoldinMeadow, 2001, Fischer, 1998, Petitto, 2000). However, the majority of parents in this study believe that what is instinctive to them - spoken language - is the most practicable route to their child's connection with family, their school learning, and future ability to work and socialise. The hope that immersion in a speaking environment will lead to spoken language proficiency and social acceptance is a key reason that parents choose mainstream schooling for their child (McKee and Smith, 2003). Parents' cultural beliefs are reinforced by a lack of exposure to the spectrum of how Deaf people use spoken, signed and written language in their adult lives. Parents also lack access to realistic information about the likelihood and impacts of restricted communication at home and school. Moreover, parents' decisions about language for a Deaf child tend to be made without conscious awareness of their own cultural set, which can obscure or limit consideration of possible options and outcomes (Beazley and Moore, 1995).

Only one-third of the surveyed parents of Deaf children in mainstream schools chose sign language for their child. Of those with profoundly Deaf children (who have the least natural access to spoken language), only half use sign language. Parents who do choose to sign typically find that a dearth of practical support hinders acquiring language skills adequate for communicating with a growing child. As the mother of a twelve-year-old in this study commented, 'Before it was okay, it was just the basics. Now she's older and her language is more advanced I find it hard [to talk about more complicated things]... a bit frustrating for both of us.' Other parents regret that sign language was offered only after years of limited communication with a pre-schooler.

Language learning for adults is a time-consuming commitment, and on an emotional level can challenge one's sense of competence and even identity. Logistical challenges also abound. Learning opportunities are especially scarce in provincial areas that rarely have NZSL classes, Deaf tutors, or even a Deaf community. Elsewhere, it is still 'hard for an entire family to go to night class' - it is expensive and impractical for siblings to attend evening classes designed for adults. Parents suggest the need for alternative means such as video materials and an 'affordable tutor to do home visits.' One parent reflected on how the misfit between learning opportunities and their needs affects their confidence: 
$[F]$ amily access to sign language is nil. We try to go to sign language classes run for teachers and teacher aides. We often feel intimidated by professionals also attending and receive unhelpful comments from people in the wider community who don't understand how difficult it has been for us to learn to sign because we have it so rarely.

In an unusual reversal of normal language acquisition roles, parents often end up learning sign language from their child, as this mother states: 'There is no support for hearing parents to learn NZSL. I learned from my daughter'. Given that language and culture are normally transmitted from older expert to younger novice, this situation is hardly an enriching basis for the mediation of a child's linguistic, cognitive and emotional development through family interaction (cf. Vygotsky, 1978).

For families who speak a minority language at home, use of sign language may be seen to threaten other cultural priorities. This Arabic-speaking mother explained how cultural imperatives motivated them to stop using sign language with their Deaf daughter (now mainstreamed, with a cochlear implant), despite its obvious practicality for the child:

[At the Deaf school the child formerly attended] they used sign language, but the difficulty is I can't understand her so they advise me to go there to have lessons to know how to sign to her. And I went there for about a year - once a week sign language. And I can understand her and I was very excited to know how she can explain her feelings, express herself.

So you felt you could communicate better after she started signing?

Yes. But although we want for her better, we want her to speak better than signing because not everyone can understand her, especially our community. We live with our community, you know? We contact them every time and they ask us, 'What's she saying?' Even my friends were prepared to know signing to help her more, yeah. But I said to them, 'No I want her to speak.' Maybe because we are very religious.

She started signing and then the English language and the signing the bridge for her to understand English language. And from English language I can make her understand Arabic. 
The pressing need to communicate in a familiar language motivates some parents to learn an artificial sign system (signs used in English word order) rather than NZSL. This is because it is seen as easier to learn and more conducive to acquisition of English, and also because the resources of the NZsL community are scarcer and harder to access than self-help tuition from a book or hearing professionals. As one parent said:

$[W]$ e wanted her to have access to oral language as well as sign. When we chose signed English there was a dictionary available for us to use at home, and because of our rural isolation, there was no one to regularly help me learn sign language. Our family needed to communicate immediately with our daughter.

Another parent said, 'We had access to signed English classes through Polytech. There is a move to NZsL but our area has no tutor. A weekend workshop twice a term is inadequate.'

Once the initial crisis of early communication has passed and schooling has begun, it is not uncommon for parents who started using sign language when their child was young to abandon signing or exhaust the available resources. Eleven percent of parents surveyed had previously used sign language and stopped. Reasons given included: advice following cochlear implantation, signing only as a transitional tool for early communication until speech begins to emerge, a wish to 'normalise' the child's language use at school, and a lack of opportunity for families to further their sign language skills. Some parents also felt rejected in encounters with Deaf community members who emphasised differences between Deaf and hearing values about being Deaf. Parents who have taken important steps towards linking their child to Deaf world resources may thus be stymied by the absence of conditions to support that decision. The result is that children for whom signing is a known and possibly preferred way of communicating lose access to this cultural tool during critical developmental years.

Parents' and children's exposure to sign language is largely on an individualised basis, over a short period - through tuition from hearing professionals, reference to books and videos, or by attendance at an evening class. This account is typical:

[When she was a pre-schooler] we had lessons of learning some signs.... The Adviser used to come here and see my daughter and they would spend say half an hour. And then they had classes down 
at the Special Education place for a little while. And then the Speech Therapist finished and she moved away and that was the end of that. But the Adviser was up until she went to school.

Such input greatly assists early parent-child communication, but does not give the full picture. NZSL, like all languages, really exists in a community of speakers and is best acquired through interaction with people who use it fluently in their everyday lives. It is rare for hearing professionals, such as those mentioned in the quote above, to have real communicative competence in NZSL (as opposed to vocabulary knowledge), or to participate in a signing community outside of paid hours. Parents seldom encounter early advice or role modelling from professionals which informs them that NZSL is a language used by a community of Deaf people who have linguistic and cultural knowledge that can help them and their child to communicate and to learn. They are not routinely introduced to people from that community who can guide them, nor provided with realistic background information that prepares them for finding a connection with the Deaf world.

\section{GATEKEEPING ACCESS TO THE DEAF WORLD?}

Only half the children were reported to have contact with Deaf adults, mainly on an occasional basis. Twenty-seven percent of parents reported contact with a Deaf Mentor or NZsL tutor, reflecting the newness and scarcity of this service. Most parents were positive about the contact they had experienced - 'The new system of mentoring has helped the whole family to learn.' Others liked the prospect - 'Would be nice for Deaf Resource Person to visit to build up my children's confidence.'

An earlier survey of parents of Deaf and hearing impaired children (Stockwell, 2000 ) found that $44 \%$ of parents identified a great need for the development of positive self-identity, yet only $21 \%$ saw contact with other Deaf children as beneficial, and even fewer (12\%) identified contact with Deaf adults as relevant. Both studies show that while most parents do not regard minimal Deaf contact as a 'gap', some intentionally avoid it. Some, however, value such contact, describing the increased confidence of their child in the company of other Deaf people, and noting Deaf Mentors' impact on raising the cultural awareness of the school.

Deaf Mentors identify their main goal with students as developing language and communicative competencies necessary to a Deaf person. In this, they view NZSL as an essential foundation for interpersonal skills, cognitive devel- 
opment and clear identity. However, they are usually assigned to work with children and parents who are already signers and/or needing remedial input, whereas they believe they have a relevant contribution to a wider range of children. One Mentor who is bilingual in spoken English and NZsL believes that the criteria professionals use to identify children who are 'Deaf enough' to benefit from their support are restrictive and misinformed, saying:

Most teachers feel that oral Deaf students don't need me to work with them. They feel they're okay on their own at school. I don't agree with that, because it's a matter of their identity...knowing who they are, being aware that there is a Deaf culture, and having the opportunity to ask me lots of questions. I sometimes say to students - 'Why don't you ask your teacher about these things?' and they always give the same answer: 'They don't understand because they're not Deaf like you. I can't really talk to them the same, they don't understand me.' But most teachers [of the Deaf] think that they do understand Deaf children. I think many of them have some fear of signing and almost try to keep me away from oral students. I've had to prove to them that if a child is oral, I will speak to them. If they seem comfortable with it I'll introduce a little bit of signing and they can see me using both [languages]. Then the student will ask why I use both, and I can explain about knowing two languages and that sometimes I use an interpreter if I want to. I believe it's very important for them to be aware about interpreters for their future lives.

Professionals' hesitation about Mentors' contact with students and parents is perceived by Mentors as gate-keeping access to knowledge of the Deaf world. One Mentor said:

Some teachers and advisers don't seem to understand my role, or they are reluctant to let students have contact with me. They seem anxious that I might lead them astray into the Deaf world, and away from the hearing world, or something. They say the family isn't ready to meet a Deaf person - they think I'll frighten them, and that they need to deal with a hearing professional. Why would I frighten parents?! I have not yet been introduced to a family of a cochlear implant child or a prospective cochlear implant family. I think that's wrong, because at the end of the day, the child is still Deaf. 
Like other bicultural minorities, Deaf experience suggests that children who are immersed in the majority culture inevitably feel themselves to be different. Without affirmation of their 'other' latent identity they are more likely to experience low self-esteem and to struggle during young adulthood to establish an integrated personal and cultural identity (Kannapell, 1991).

At issue here is the cultural territory that the Deaf child has membership rights to, and who decides which cultural images are relevant to children's self-knowledge. Deaf Mentors value the connectedness of Deaf people and the importance of passing on Deaf experience (regardless of individuals' use of assistive technology, communication mode, or degree of hearing loss); this clashes with the normalising imperative that dominates educational responses to Deaf children. The assumption that meeting a Deaf adult would 'frighten' hearing parents is understood by Mentors as a pejorative belief that Deaf people - even those employed in the education system - may confront parents with an unpalatable embodiment of 'otherness' which they might find incompatible with their image, and not want to associate with their child. Consistent with this is Mentors' observation that NZSL and Deaf input is frequently regarded as a remedy of last resort, rather than a core cultural resource:

My experience is that they will call on me after a couple of years, if things aren't working well and the child hasn't developed good speech - then they will want me to teach them NZsL, once they have a major language delay. Even if they don't sign, why can't they just meet me, as one Deaf person to another?

'BEING THE SAME' OR 'LIVING IN TWO WORLDS'

A chief reason that parents choose mainstream schooling for their Deaf child is the hope that this experience will 'give a better chance at living in the hearing world'. Some parents broach the idea of participation in two cultures: 'Mainstreaming is the best option to enable our child to live in both worlds', and, 'If he so chooses when he is older to turn more to the Deaf culture that's fine. These statements reflect incipient awareness of the Deaf community, but perhaps little appreciation of routes of socialisation into it, or its potential as a resource for the early development of a Deaf child's life skills.

Regardless of ethnicity or communication mode, the parents interviewed all described their child's immediate comfort with other Deaf people; for example: 'When I saw him at the Deaf school that time he visited, he clicked just like that. It was like an instinctive thing...just fitted in.' 
Nevertheless, hearing parents commonly believe that Deaf schools or units distance Deaf children from normal society, limiting their communication skills, aspirations, opportunities and academic achievement - in effect, 'ghetto-ising' them. Professional advice, the quality of education available, and little exposure to groups of Deaf people all contribute to this perception. The mother of a nine-year-old Deaf boy who has significant social and academic difficulties at school voices this perspective:

[professionals] suggested that [going to a Deaf unit] was actually going to make him more Deaf.... I really probably wanted him to be mainstream, you know. And I mean, a lot of the kids up there [at the Deaf unit] are really very Deaf and they don't talk properly whereas he has quite good speech.... I would [send him to a Deaf school] if it meant that he would catch up, that he would learn better social skills.... But is it the answer?

Ability to speak is equated by this mother to near-normality, of not being Deaf enough to identify with Deaf children, even though her Deaf son's interaction with hearing peers is superficial and difficult. Contact with Deaf children who use sign language is perceived by his parents and some professionals as jeopardising his success in the hearing world. Deaf, in this context, clearly implies a stigmatised category of 'others'. The mother's final rhetorical question suggests apprehension without insight about the potential impact of Deaf social contact on his future.

Although Deaf parents of Deaf children often choose mainstream schooling for bicultural and academic reasons, Deaf parents in this study also valued the interactional advantages that a critical mass of Deaf, signing peers affords a Deaf child. This Deaf mother explained that she saw a Deaf school setting as a good milieu for her son's educational and social future, 'because of all the children signing there. They can learn things quickly and when they grow up they know everything. Signing is good for the mind.'

Without knowledge of how Deaf adults manage participation in two social worlds, hearing parents struggle to balance knowledge of their Deaf child's easy affinity with Deaf peers against the prevailing image of a successful future as being in the hearing world. Unlike Deaf parents, hearing parents generally have no picture of a Deaf community as a point of reference for interpreting their child's experiences, or weighing up the relative importance of Deaf social connection in relation to belonging to the family's community. 
The story of Simon (one of the case studies within the mainstream project) illustrates the inconsistent information and goals upon which parents may base decisions that have far-reaching effects on social identity and educational outcomes. Simon (at the time of the study) is a ten-year-old profoundly Deaf boy living in a provincial town with his mother and two brothers, attending a local school. His parents followed professional advice to use Signed English from early pre-school years, and at school his two teacher aides and some classmates can sign at various rudimentary levels. He has had little exposure to Deaf NZsL signers or role models of any age, although his signing appears more 'Deaf' (in the character of NZSL) than English-like. At the age of six, his parents chose cochlear implant surgery for Simon, in the hope of achieving speech skills that would 'improve his opportunities in the hearing world'. Four years later, at ten, he can understand routine verbal instructions (such as, 'get your maths book', 'take your jersey off', 'unpack your bag'), but new information needs to be signed in order for him to understand.

At the age of eight, and again at age ten, his parents became quite dissatisfied that Simon's speech was still not very intelligible. They were advised by a speech therapist and audiologist in the cochlear implant program to stop using sign language so that he would have to rely totally on listening and speech. This decision was implemented at home and at school. The teacher aides were concerned about his ongoing need for visual language, since tests had previously shown him to have an auditory-verbal memory of a maximum string of eight words - insufficient to process or comprehend much spoken language in class, even if he could distinguish the words. Each time signing was withdrawn, behaviour problems manifested. For example, in class Simon would often refuse to look at the teacher, the board, or the aide who would write notes or draw pictures (rather than signing) to help him follow. When prompted to watch he angrily says, 'I'm listening, I can hear everything, I don't need to look!' In response to comprehension checks, he responds, 'I know, I know!' but cannot explain the information. The aide reported that Simon says he can hear sounds, 'but it's all jumbled up in my head'.

His 'difficult behaviour' was handled by a behaviour modification chart, awarding stars for demonstrating attentive listening and co-operative behaviour. From this, Simon would learn the value of being passive and not showing when he feels confused, anxious or angry that he can't understand what's going on. He is learning to 'pass', to fit in by displaying acceptable hearing behaviours. Three months after the second withdrawal of sign language, it 
was clearly not working well at school. The approach was modified to allow teacher aides to sign selected activities, such as story reading and discussions, but not maths ('it's so visual' according to an aide), or public events like assembly. At home, his mother continued to use 'key signs' only as a last resort for communication.

An interview with Simon's mother following the second withdrawal of signing reflects a sense of uncertainty and discontinuity about his current and future linguistic and social identity:

Do you see him then, as a teenager or young adult, not using sign language as one of his languages?

No, because I actually think that that'll be his choice. Without the cochlear he is still Deaf but even with the signing, the thing is he has a mish-mash of languages. He still doesn't own one type of sign language - it's made up of New Zealand Sign Language and Australasian [Signed English] - so he's actually got nothing, he hasn't got one solid thing. So the focus is getting him to have speech production.

Do you think it will still be important for him to connect with other Deaf people?

Oh yeah definitely, because I mean, it's a culture really.... I mean I've heard Deaf adults say that they grow up in isolated areas like this and they ended up moving to places where there was a Deaf community, because they just felt more at ease...but the reality is that you just can't pack up your life and move.

Simon's mother's responses above express her awareness of a potential Deaf identity, yet this is qualified by what she understands to be the inevitable constraints of their situation. There is an inherent disjunction between the choices being made for him now, and an acknowledgment that he may well identify with the Deaf world later.

Signing, in Simon's situation, is apparently not regarded as a language as such, but rather an adjunct to speech and a pedagogical tool, even though his sign language is far in advance of his spoken language competence. This is reflected in his mother's comment about the 'mish mash', the 'nothing' she describes him as having, to which speech seems a tidier and more certain alternative. Although all of his learning and social interaction had been me- 
diated through signing until the age of eight, it was considered advisable to withdraw it abruptly. Inconsistent guidance from educational and medical professionals such as this casts sign language as a transitional, dispensable mode of communication, rather than a language integral to the child's cognition, socialisation and self-concept.

When I asked Simon's mother whether getting the message that signing was no longer acceptable might have had a negative emotional impact on him, she considered this and replied:

Actually, it would probably raise self-esteem issues. Probably when you think about it, because I'm not in a Deaf community and I'm in the hearing world, maybe that's the side I tend to overlook. You think you're doing things always for his best interest - I mean any parent's like that - but I wonder, if he's seventeen and he says, 'But I remember when I was twelve you made me take away the signing.' I don't know, maybe he's gonna come back and say that....

Aware of the meagre linguistic and cultural support for being Deaf in her son's current context, this mother expresses some anxiety about her choices. But, within the available model of successful outcomes, she understandably hopes for his integration into the hearing social world in which his family is located. The school's 'individual-special-needs' orientation to deafness is consistent with this aim. The school principal saw little relevance of Deaf culture or identity to Simon, as expressed in this exchange:

Do you see that there's any benefit for him in having contact with other Deaf kids?

Only as much as having contact with other kids. I don't know that he necessarily sees himself as a Deaf person. It's not that strong Deaf culture thing. He's not in that is he? His family are not really into the Deaf culture thing, so I don't know that.... As he's not signing anymore [pause].... I mean it's like saying that people in wheelchairs like to meet other people in wheelchairs. Not being in that situation myself, I wouldn't like to make a decision.... I don't really think he would care particularly.

The simile with 'people in wheelchairs' signals an understanding of deafness as physical impairment. Even so, the assumption that neither Deaf nor physically disabled people would have any natural interest in meeting others like 
themselves betrays little awareness of minority group experience, and an uncritical belief that integration by assimilation is universally desirable. Consistent with this stance, the principal described Simon as 'hearing better' and participating more normally since the withdrawal of signing, commenting:

he does hear and he does have his say and he's expressing himself verbally. So he's obviously picking up, he's hearing what we say and he's understanding and he's having his input as well. Whereas he wasn't able to do that so readily because the signing left out quite a few...there seemed to be gaps in his understanding, I felt.

The expressed belief here is that signing limited Simon's access to language and inclusion, whereas ceasing to sign has increased his access to spoken language and normal interaction. My observation in class over several weeks was that his speech consisted of short, perfunctory utterances, usually for functional rather than discursive purposes, and was quite difficult to understand. Nevertheless, it appears that his verbal 'input' is evaluated more positively than his previous signed input, as it is more accessible to the majority language speakers.

Simon's mother, at this point, was clearly grappling with competing images of Simon's sociolinguistic identity and future - one of which felt more palatable than the other at this point on her journey. The year after this research, Simon's parents decided to transfer him to a residential Deaf school where he has access to NZsL with Deaf peers and adults, and where he is flourishing. This decision and his physical move into a Deaf community marked an important, non-reversible step for Simon and his parents on a journey towards the Deaf world, where he is likely to find footing as a young adult.

'THE NEIGHBOURS HEAR YOU, BUT SHE CAN'T':

CULTURALLY ADAPTED STRATEGIES FOR INTERACTION

Simon's story illustrated the conventional preoccupation with Deaf children's deficit in hearing and listening. Copious professional and parental effort is directed towards redressing this. Even if they also value acquisition of spoken language, however, Deaf parents (such as Buzzard and Nicholson, this volume) and bilingual educators take a different slant. They stress the importance of equipping hearing parents with pragmatic strategies for interacting with children in ways that are visually accessible, thus more relaxing and conducive to affective and cognitive engagement in communication (Mather, 
1989, Mather, 1994, Mohay et al., 1998, Marschark et al., 2002).

This study shows a need for parents and Deaf children to have early exposure to Deaf people who can model the pragmatic skills of visual communication such as important attending and turn-taking behaviours that are regulated by sight and touch, rather than hearing. Without this alternative knowledge, parents can easily frame Deaf children as deficient in appropriate listening and communication behaviours, and themselves as perhaps inept in communicating with them. On a daily basis, issues around communication behaviours can become a major source of tension in Deaf-hearing relationships. Ricky's mother, below, knows that different strategies are needed, but lacks information and models to guide and interpret her son's behaviour differently:

I have to yell a lot.... It's all that much more tiring because you've got to go to him.... I mean I can talk to my other son and he'll come to me.... Whereas Ricky just doesn't hear at all.... [My partner] is partially Deaf, so he is always in front of Ricky when he talks...and he always gets people's attention first - says 'Look at me' - whereas Ricky gets himself in a tizz and expects everyone to run to him.... And he hasn't learnt to listen either. You know, he tends to go off, whereas he hasn't really listened to what you've been trying to say. So he loses it.

Ricky's mother was also frustrated that he did not show seemingly 'logical' strategies for paying attention in group situations, attributing this to his lack of commonsense and awareness of his 'problem', as this account reveals:

He got into the regional team last year and I said to him, 'You know, you've got to get in front of your coach, you've got to watch her lips, you've got to try and listen.' And he says, 'I don't need to because I stand at the back of the line.' But everyone that stands at the back of the line, they get left behind... he is very good physically, but he can't figure that he would benefit if he stands at the front of the line - in front of the coach.... Like he prefers to stand at the back of the line so that he can see what they're doing. Whereas if he stood in front of the coach he could see what was expected of him. I'm just saying mentally, human logic would tell you, 'Now I've got a problem, if I stand in front I can be in front of everybody, I can be on top of it like everybody else if I stand in front and listen to it.' But he doesn't figure that out for himself. 
Until her conversation with me, this mother was not aware that it is a common strategy for Deaf people to position themselves at the edge of a group so that various speakers and actions are within their visual field, rather than being at the front with their back to other participants. More basically, she assumes that her Deaf son would, logically, 'know' that the movement of lips is a meaningful source of information. For Deaf people, the experience of watching lip movements is so often unrewarding that they may, logically, choose to ignore this and take their cues from actions. Also, in the figuring of a Deaf child in this social situation, the need to blend with peers no doubt ranks more highly than the need to get information from an adult.

Another mother laughed over her husband's communication with their twelveyear-old: 'He talks to her [without signing]...sometimes really loud. But I say 'Don't do that "cause the neighbours hear you, but she can't!"

Although speaking loudly to a Deaf person seems perhaps natural or trivial, it exposes a lack of strategies better adapted for visual communication which can be readily learned from interaction with Deaf people. Another mother related that, 'If I'm saying something to the other kids, I've always sort of got my hands going and shifting my eye-contact so that he's not always excluded, because sometimes it does happen that way and he might say, "What are you laughing about?"”

Parents clearly can and do learn to adapt family communication dynamics to include a visual communicator, even though this might be effortful. (The same mother added candidly, 'If I'm tired sometimes I find him demanding and I just think "Oh God, I wish you could talk."')

\section{IMAGES OF DEAF CHILDREN AS LEARNERS}

Linked to images of Deaf children as communicators are images of them as learners. They are at risk of being characterised as having unusual difficulties with learning, which in fact often transpire from the disabling circumstances in which they find themselves. This mother's description of her son's learning illustrates this phenomenon:

There's lots of Deaf children that are very bright and developed really well whereas he's always been backward.... I said to them [on a visit to the Deaf Education Centre], I think there's something mentally wrong with him. And they said that he absorbs very well visually but he doesn't orally. But I mean that's pretty obvious in the fact 
that he's very good at sports and things like that because it's very visual...but he doesn't get it academically.

The observation that a Deaf child seems to learn visually (although not a signer) rather than orally/aurally, is, from a Deaf perspective, an entirely predictable trait. Deaf Mentors identified the learning difficulties of Deaf students in mainstream schools as evidence of ill-adapted learning environments for a Deaf person.

Ricky's mother struggled to understand how a Deaf child conceptualises and learns so differently from a hearing sibling, who has constant access to incidental communication:

I can't understand why he doesn't pick up certain concepts. Like we were reading a book and it said about 'neighbour', and I said, 'A neighbour is the person that lives next door.' And you know, they were saying about how you visit. And he said, 'Where's the gate to go next door in the picture?' Like, as if it really matters! ... He's always been very realistic. You know if he reads a book and there's a picture of a cat - sometimes they do really funny looking cats - and he'll go, 'That's not a cat, that doesn't look like a cat.' Everything has to be very realistic.... There isn't a logical reason for everything, but he needs to have that logical reason for everything. If there isn't, he can't piece it together.... I mean I find it confusing. I'm not really quite sure or really understand what it is.

This lack of insight about the constrained linguistic input and general knowledge available to Deaf children contributes to an image of her child as "backward' and unusual. While some parents had high expectations for their child and made extraordinary efforts to achieve these, others accepted that their child would achieve at lower levels because of the limitations they saw as intrinsic to being 'Deaf in a hearing world'. The importance of exposure to successful Deaf learners and Deaf parenting role models cannot be overstated in response to altering parents' insights and images.

\section{CONCLUSION}

To begin migrating and for the journey to progress successfully, stronger mechanisms for connecting parents to the diverse perspectives and readymade strategies that Deaf people can offer Deaf children are needed. Instead of retracing well-trodden paths and pitfalls, the experience of raising Deaf 
children and growing up Deaf should evolve from the state of knowledge already achieved by previous generations. Of course, the particular historical journeys and landing points of current Deaf community members may not all necessarily be exemplary models, and naturally the context of social and technological conditions changes with each era; yet the essential existential challenges do not alter for Deaf people.

Connecting hearing parents and their Deaf children to the Deaf world requires a different mix of participants and ideas in the 'system' surrounding them. More Deaf people, as well as those with intercultural skills such as coDAs (Children of Deaf Adults), interpreters, and parents of mature Deaf people, who are motivated and able to broker intercultural contact need to be involved. Since the language and life experience of the Deaf community has begun to be acknowledged and validated, more people with Deaf world backgrounds are entering roles in the educational arena. The introduction of paraprofessional Deaf Mentors is an example of a strategy enabling Deaf children and their families to connect with the Deaf world. Contact with Deaf Mentors' values, behaviour, language, and personal histories provides a social context in which parents can begin to appreciate an alternative construction of deafness.

Also fundamental to relationships between Deaf people and their families is a shift in the underlying balance of power between Deaf and hearing people at institutional and individual levels. Control of language and communication (and thus identity) choices is at the hub of this dialectic. Debate about the relative value of sign language and cochlear implants as tools in Deaf people's lives is a current expression of this tension, as seen in Simon's story. Deaf writer Tom Humphries (1996) observes that the contemporary Deaf consciousness is voicing a long-concealed rejection of hearing-constructed images of Deaf people's selfhood, emphasising distance or 'distinctness' from hearing culture as part of an agenda for self-determination. This is the socio-political context that makes sense of Laing's (this volume) puzzlement that her migration was 'sidetracked by how Deaf people responded when I approached them. I thought they would want to meet this new member of their culture and her family'. It is also the backdrop to Deaf Mentors' expressed frustration about restrictions on their sphere of influence.

In building the connections that are mutually necessary between Deaf and hearing people who must co-exist, Humphries recommends 'deference' (after Scollon and Scollon, 1981) as a key disposition for participants. Both sides need to recognise differences, acknowledge historical inequities, and respect 
the other's need for autonomy. The nature of contact between parents of Deaf children and representatives of the Deaf adult world is a rich and significant potential site for further research. The evidence so far suggests that there is intercultural diplomacy work to be done to equip professionals, parents, and Deaf people to forge connections that might contribute to clearer paths for young Deaf people.

\section{ACKNOWLEDGMENTS}

I am sincerely grateful to the anonymous research participants who shared their experiences with me in this enquiry, and appreciate Tricia Laing's encouragement to write this article. Eileen Smith, Alan Wendt, Wenda Walton and Kirsten Smiler provided research assistance with transcription and coding of data that contributed to this article. Funding for this research was provided by the Faculty of Humanities and Social Sciences, Victoria University of Wellington.

\section{NOTES}

1 From the poem, 'To a Hearing Mother' by Deaf poet Ella Mae Lentz, (Lentz, 1995)

2 Capitalised 'Deaf' is used in this article in accordance with the preferred usage of Deaf people, to whom it denotes their sense of linguistic and cultural identity, in contrast to 'deaf' as generally used to describe the audiological status of an individual. In each case of a Deaf child born to hearing parents it is variable as to whether and when they develop a 'Deaf' cultural identity. Nevertheless, I use this convention throughout to refer to adults, children, and the Deaf collective, for the sake of consistency, and in keeping with my position that all such individuals are potential members of a Deaf culture and community.

3 This was formally acknowledged in a policy document for Deaf education (DEANZ, 2003).

4 The larger project focused on 'high needs' and 'very high needs' Deaf students in New Zealand mainstream schools, examining their classroom interaction and learning. The project included six case studies, and national surveys of adult stakeholder groups: parents, mainstream teachers, teacher aides, teachers of the Deaf; it is reported at: http://www.vuw.ac.nz/lals/research/deafstudies/ DSRU\%2osite/index.aspx. 


\section{REFERENCES}

Ahlgren, I. \& Hyltenstam, K. 1994 Bilingualism in deaf education, Hamburg: Signum.

Bailes, C.N. 1999 'Deaf-centric teaching: A case study in ASL-English', in Bragg, L. (ed) Deaf World: A historical reader and primary sourcebook, New York: New York University Press.

Beazley, S. \& Moore, M. 1995 Deaf children, their families and professionals: Dismantling barriers, London: David Fulton Publishers.

Branson, J. \& Miller, D. 1993 'Sign language, the Deaf and the epistemic violence of mainstreaming', Language and Education, 7 (1).

Chamberlain, C., Morford, J. P. \& Mayberry, R. I. 2000 Language acquisition by eye, New Jersey: Lawrence Erlbaum Associates, Inc.

DEAnZ, (Deaf Education Aotearoa New Zealand) 2003 National Plan for the Education of Deaf and Hearing Impaired Children and Young People in Aotearoa/New Zealand. Wellington, Ministry of Education.

Fischer, S. D. 1998 'Critical periods for language acquisition: Consequences for deaf education', in Weisel, A. (ed) Issues unresolved: New perspectives on language and deaf education, Washington DC: Gallaudet University.

Goldin-Meadow, S. 2001 'Learning with and without a helping hand', n Landau, B., Sabini, J., Jonides, J. \& Newport, E. L. (eds) Perception, cognition and language: Essays in honor of Henry and Lila Gleitman. Cambridge, Massachusetts: Massachusetts Institute of Technology Press.

Grosjean, F. 1998 'The right of the deaf child to grow up bilingual', Deaf Worlds, 15: 29-31.

Holcomb, T. 1997 'The development of a deaf bicultural identity', American Annals of the Deaf 142: 89-93.

Humphries, T. 1996 'Of Deaf-Mutes, the strange, and the modern Deaf self', in Bragg, L. (ed) Deaf World: A historical reader and primary source book, New York: New York University Press: 348-364. 
Johnson, R. E. \& Erting, C. 1989 'Ethnicity and socialisation in a classroom for deaf children', in Lucas, C. (ed) The sociolinguistics of the deaf community, San Diego: Academic Press Inc.

Kannapell, B. 1991 'The Relationship of Deaf Studies and Deaf Identity', The Deaf Studies for Educators Conference. Dallas, Texas.

Kuntze, M. 1998 'Literacy and deaf children: The language question', Topics in language disorders, 18:1-16.

Kyle, J. 1991 'Unit 2: The Deaf Community', in Kyle, J., Gregory, S. \& Miles, D. (eds) Being Deaf: The Deaf Community, British Sign Language, Communication \& Deafness (Block 1), Milton Keynes: Pinter/The Open University.

Ladd, P. 1991 'Making plans for Nigel: the erosion of identity by mainstreaming', in Taylor, G. \& Bishop, J. E. (eds) Being Deaf: The experience of deafness, London: Pinter Publishers, in association with The Open University: 88-96.

Ladd, P. 2003 Understanding Deaf Culture. In Search of Deafhood, Clevedon: Multilingual Matters Ltd.

Lane, H. 1992 The Mask of Benevolence: Disabling the Deaf Community, New York: Alfred A. Knopf Publishers.

Lentz, E. M. 1995 The Treasure. Poems by Ella Mae Lentz (videotape). Berkeley, CA: In Motion Press.

Mahshie, S. N. 1995 Educating deaf children bilingually, Washington DC: Gallaudet University Press.

Marschark, M., Lang, H. G. \& Albertini, J. A. 2002 Educating deaf students: From research to practice, Oxford: Oxford University Press.

Martin, D. S. \& Lytle, R. R. 2000 'Deaf teacher candidates in hearing classrooms: A unique teacher preparation programme', American Annals of the Deaf, 145(1): 15-22.

Mather, S. 1989 'Visually oriented strategies with deaf preschool children', in Lucas, C. (ed) The Sociolinguistics of the Deaf Community. San Diego, CA: Academic Press. 
Mather, S. 1994 'Adult-Deaf toddler discourse', in Snider, B. D. (ed) Post-MilanASL and English Literacy: Issues, Trends, and Research. Washington DC: Gallaudet University College for Continuing Education.

Mckee, R.L. 2005 'As one Deaf person to another: Deaf paraprofessionals in mainstream schools', Deaf Worlds, 21.

Mckee, R.M.L. \& Smith, E. 2003 Report on a Survey of Parents of 'High' and 'Very High Needs' Deaf Students in Mainstream Schools. Wellington, Deaf Studies Research Unit, Victoria University of Wellington. http://www.vuw. ac.nz/lals/research/deafstudies/DSRU\%2osite/index.aspx

Mohay, H., Milton, L., Hindsmith, G. \& Ganley, K. 1998 'Deaf mothers as communication models for hearing families with deaf children', in Weisel, A. (ed) Issues Unresolved:New Perspectives on Language and Deaf Education. Washington D.C.: Gallaudet University Press: 76-87.

Patton, M. Q. 1980 Qualitative evaluation methods, Beverly Hills: Sage Publications.

Petitto, L. A. 2000 'The acquisition of natural signed languages: Lessons in the nature of human language and its biological foundations', in Chamberlain, C., Morford, J. P. \& Mayberry, R. I. (eds) Language acquisition by eye, New Jersey: Lawrence Erlbaum Associates, Inc.: 41-51.

Pickersgill, M. 1997 'Towards a model of deaf education for deaf children', Deafness and Education (JBATOD), 21(3):10-19.

Schleper, D. R. 2002 Reading to deaf children: Learning from deaf adults, Washington DC: Laurent Clerc National Deaf Education Centre, Gallaudet University.

Scollon, R. \& Scollon, S. 1981 Narrative, literacy and face in interethnic communication, Norwoord, NJ: Ablex.

Smith, E. 2003 'Deaf Ways': The literacy teaching strategies of Deaf teachers in New Zealand. Unpublished Masters Thesis, Victoria University of Wellington.

Stewart, D. A. \& Kluwin, T. N. 2001 Teaching deaf and hard of hearing students: Content, strategies and curriculum, Needham Heights: Allyn and Bacon. 
Stockwell, W. 2000 Establishing Deaf Children's Educational Needs. Report for Specialist Education Services, Wellington, New Zealand.

Vygotsky, L. S. 1978 Mind in Society: The Development of Higher Psychological Processes, Cambridge, MA: Harvard University Press.

Woodward, J., Allen, T. \& Schildroth, A. 1988 Linguistic and cultural role models for hearing -impaired children in elementary school programmes, in Strong, M. (ed) Language learning and deafness, Cambridge: Cambridge University Press. 